\title{
Atresia of the right atrioventricular orifice
}

\author{
ROBERT H. ANDERSON, ${ }^{1}$ JAMES L. WILKINSON, LEON M. GERLIS, \\ AUDREY SMITH, AND ANTON E. BECKER
}

From the Departments of Paediatrics, Brompton Hospital, London; Child Health, University of Liverpool, Liverpool; Pathology, Grimsby General Hospital, Grimsby; and Pathology, Wilhelmina Gasthuis, Amsterdam, The Netherlands

The results are reported of a study of 83 necropsied hearts with atresia of the right atrioventricular orifice. It is emphasised that right atrial or atrioventricular orificial atresia is a better term to describe this anomaly than 'tricuspid atresia'. Use of the latter term can be confusing when the morphologically tricuspid valve is located beneath the left atrium. It is accepted that the definition employed may include cases in which the mitral valve may be atretic, blocking normal exit from the right atrium, but it is argued that such cases would present clinically as 'tricuspid atresia' and therefore are correctly designated as right atrial orificial atresia. The results show that the majority of hearts with right atrial orificial atresia have the ventricular morphology of primitive ventricle, most with, but a few without an outlet chamber. However, in a minority of hearts an imperforate membrane interposes between the right atrium and a formed but hypoplastic right ventricle. In two of the hearts, the imperforate membrane showed features of Ebstein's malformation. The hearts could be further subdivided according to the ventriculoarterial connection. Most had normally connected arteries (66 of 83), and all but 2 also had normal relations between the arteries; in these 2 hearts there was 'anatomically corrected malposition'. Twelve hearts showed transposition, one had double-outlet outlet chamber, and another persistent truncus arteriosus. The remaining 3 hearts, all without outlet chamber, had by definition $a$ double outlet connection. A segmental approach provides the best way of classifying this anomaly, and an embryological explanation is offered for the variations in anatomy observed.

The classification of tricuspid atresia introduced by Edwards and Burchell (1949) has proved its value in clinical, surgical, and pathological settings. However, recent modifications of the original classification have perhaps detracted from its value. Using the modification suggested by Keith et al. (1958), atresia of either the right or left atrioventricular valves can correctly be described as tricuspid atresia. Definition of 'transposition' as applied to this classification varies considerably and is a potential source of further confusion. Thus, using the term 'transposition' to describe any anteriorly situated aorta, Tandon and Edwards (1974) described under the heading of 'tricuspid atresia with 1-transposition' first, hearts with right atrioventricular valve atresia in which the aorta arose from the left ventricle and secondly, hearts with left atrioventricular valve atresia in which the aorta arose from the right ventricle.

With the advent of radical palliative surgery for tricuspid atresia (Fontan and Baudet, 1971), it is ${ }^{1}$ R.H.A. is a British Heart Foundation Senior Research Fellow. Received for publication 24 September 1976 desirable to have a system of nomenclature which avoids these discrepancies. Any successful nomenclature should permit accurate description of hearts in all aspects of their anatomy, in particular with regard to the site of atrial orificial atresia and to the ventricular morphology and ventriculoarterial connections. The segmental approach promoted by Van Praagh and his colleagues (Van Praagh et al., 1964; Melhuish and Van Praagh, 1968; Van Praagh, 1972 ) is ideally suited for this purpose. We have therefore analysed a series of specimens with right atrial orificial atresia using this approach.

\section{Materials and methods}

The 83 hearts studied were all those with atresia of the right atrioventricular orifice in the pathological collections of the Brompton Hospital, London; Royal Liverpool Children's Hospital; Grimsby General Hospital; Wilhelmina Gasthuis, Amsterdam; Sint Antonius Ziekehuis, Utrecht; and selected specimens from the Department of Anatomy, University of Leiden. In all instances the 
hearts were studied so as to elucidate their segmental arrangement, paying particular attention to the ventricular morphology, and the nature of associated anomalies. Twelve of the hearts were also studied by serial histological sectioning of the atrioventricular junctions primarily in order to ascertain the disposition of the conducting tissue (J. L. Wilkinson, A. Smith, A. E. Becker, and R. H. Anderson, unpublished observations). Certain of these histological findings are pertinent to the present investigation, and will be discussed where relevant.

\section{Definitions and terms}

(1) ATRIAL SITUS

Situs solitus is present when the morphologically right atrium is right sided and the left atrium is left sided (Shinebourne et al., 1976). The other varieties of atrial situs are situs inversus and situs ambiguus.

\section{(2) VENTRICULAR MORPHOLOGY}

The terms right ventricle and left ventricle will only be used in this report when each ventricular chamber is in potential communication with a separate atrial chamber, and each ventricular chamber contains the complete tension apparatus of the connecting atrioventricular valve (Fig. 1).

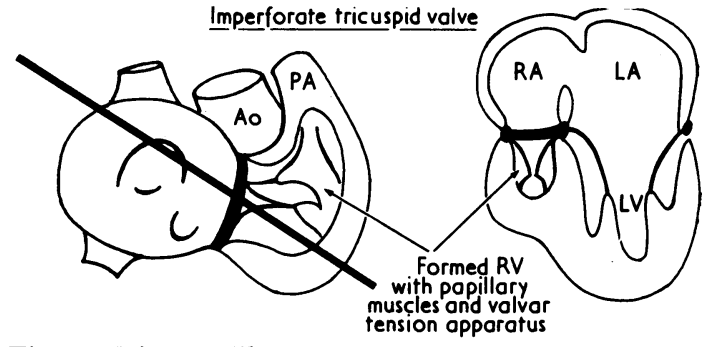

Fig. 1 Diagram illustrating the concept of a heart with formed right and left ventricles, but an imperforate membrane between the right atrium and the right ventricle. The latter chamber contains valvar tension apparatus.

In the situation in which a single atrioventricular valve is present between the left atrium and a ventricular chamber, and the blind-ending right atrium is also in potential communication with the chamber receiving the single antrioventricular valve, then the ventricular morphology is considered to be a variant of primitive (single or common) ventricle (Macartney et al., 1976; Shinebourne et al., 1976). In this situation the chamber receiving the single atrioventricular valve is termed the main chamber. If a smaller anterior chamber is also present it is termed the outlet chamber (Fig. 2). The foramen

Primitive (single) ventricle with right otrial orificial atresia

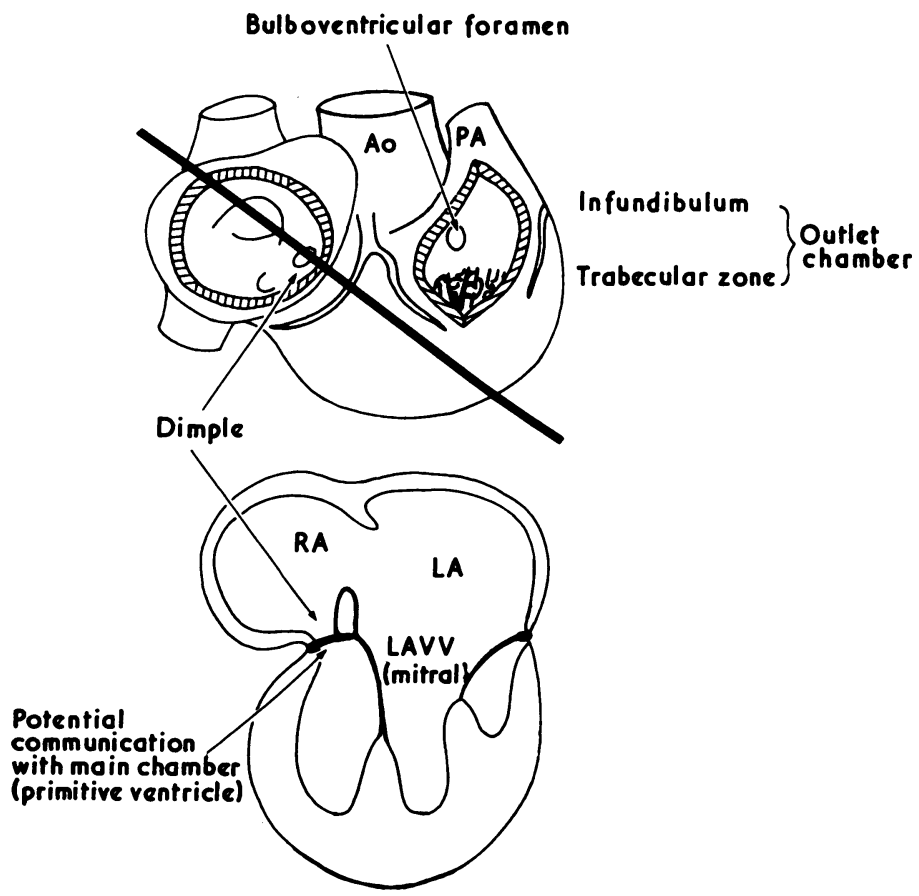

Fig. 2 Diagram illustrating the concept of a univentricular heart with right atrial orificial atresia. The blind ending right atrium is in potential communication only with the main chamber which receives the left atrioventricular valve. The anterior chamber is an outlet chamber, not a true right ventricle, exhibiting only infundibular and trabeculated zones. It does not contain valvar tension apparatus. The heart is, therefore, a variant of primitive ventricle with outlet chamber, and the communication between the chambers is the secondary bulboventricular foramen. 
between the main and outlet chambers is described as the bulboventricular foramen, remembering that if one great artery arises from the main chamber the foramen should strictly be termed the secondary bulboventricular foramen. (Compare closure of the interventricular defect by Van Mierop et al. (1963).) When a single ventricular chamber receives a single atrioventricular valve, supports both great arteries, and also is in potential communication with the blind-ending right atrium, there being no evidence of an anterior outlet chamber, then the anomaly is described as primitive (single or common) ventricle without outlet chamber (Fig. 3). The single atrioventricular valve present in the hearts to be described is termed the left atrioventricular valve. Its morphology will be described where pertinent. Since the blind-ending right atrium does not always have a fibrous membrane interposing between it and a ventricular chamber, the situation will be described as right atrial orificial atresia rather than as valve atresia. If a membrane is present, then its morphology will be described.

\section{Primitive ventricle with right atrial orificial otresia}

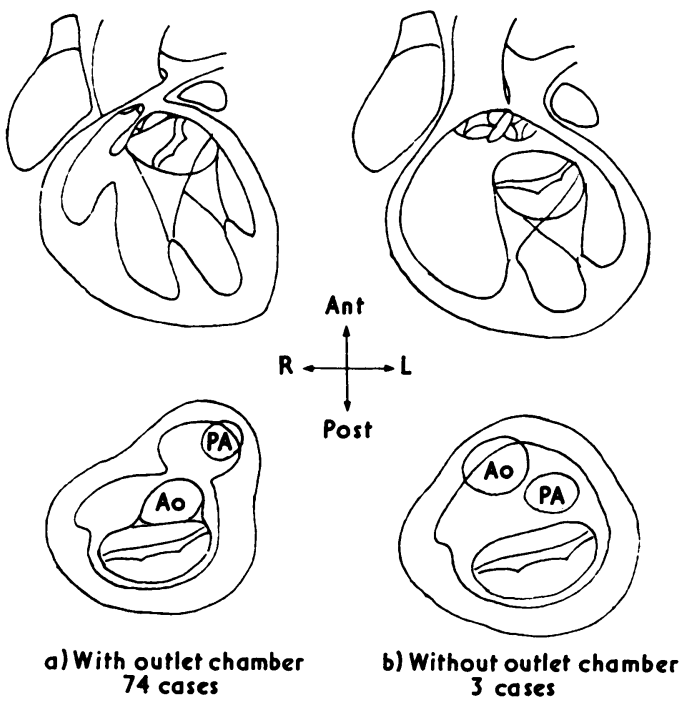

Fig. 3 Diagram illustrating the concept of right atrial orificial atresia in hearts with (a) primitive ventricle with outlet chamber and (b) primitive ventricle without outlet chamber. The numbers indicate the total of cases studied in each category. The upper panels are frontal sections, the lower horizontal sections through the heart just beneath the atrioventricular junction.

\section{(3) VENTRICULOARTERIAL CONNECTIONS}

(Fig. 4)

Normal connections describe the situation in which the aorta arises from the left ventricle or from the main chamber, and the pulmonary artery from the right ventricle or from the outlet chamber. Usually with normal connections the aortic valve is posterior and to the right of the pulmonary valve. This is described as normal relations (Fig. 4A). Occasionally normal connections exist with the aortic valve in anterior, left-sided position (Fig. 4B). This is described as normal connections with l-malposition or 'anatomically corrected malposition'. Transposition is present only when the aorta arises from the right ventricle (or from an outlet chamber) and the pulmonary artery from the left ventricle (or from the main chamber). The prefixes $d$ - and $l$-refer to the position of the aortic valve relative to the pulmonary valve whether describing malposition or transposition (Fig. 4C and D). When more than $1 \frac{1}{2}$ great arteries arise from the same chamber, the connection is described as double-outlet main chamber or doubleoutlet outlet chamber (Fig. 4E); the great arteries in double-outlet chambers are described in terms of d- or l-malposition. When a single arterial trunk leaves the base of the heart and when this single artery gives rise to the aorta, one or both pulmonary arteries, and the coronary arteries, it is described as a persistent truncus arteriosus (Fig. 4F). Other variants of single trunk are single aortic trunk with pulmonary atresia and single pulmonary trunk with aortic atresia.

\section{(4) VENTRICULAR MUSCLE BUNDLES}

In the hearts studied the muscular septum interposing between the aortic and pulmonary valves is described as the infundibular septum. Previously this structure has been termed the conus septum (Anderson et al., 1974b). If a muscular fold separates the posterior semilunar valve from the atrioventricular valve it is termed the ventriculoinfundibular fold. This previously has been termed the conoventricular flange (Anderson et al., 1974b).

\section{Results}

\section{A. ATRIAL ANATOMY}

All the hearts studied had situs solitus. The right atrium, therefore, received the systemic venous return. The only exit from the right atrial chamber was through an interatrial communication. In 77 hearts, the communication was either a secundum atrial septal defect or a widely patent foramen ovale. In 6 hearts the defect was of the ostium primum variety, in each case with a cleft in the left atrioventricular valve (Fig. 5). A further significant 


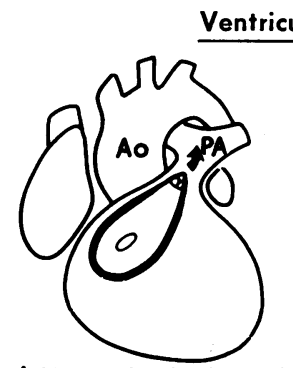

A) Normal relations -58 cases (4 with Pulmonary atresia)

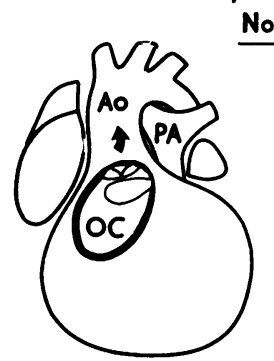

C) d-transposition-10 cases

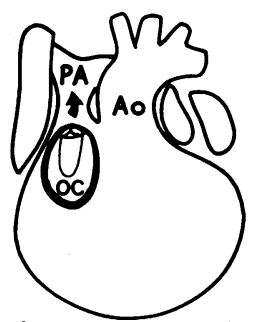

B) (-malposition -2 cases

Fig. 4 Diagram illustrating ventriculoarterial connections in 74 cases of primitive ventricle with outlet chamber and right atrial orificial atresia, and the number of specimens studied in each category.

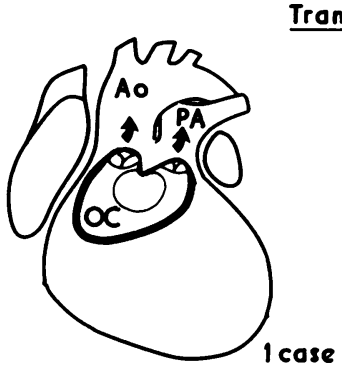

E) Double outlet (outlet chamber)

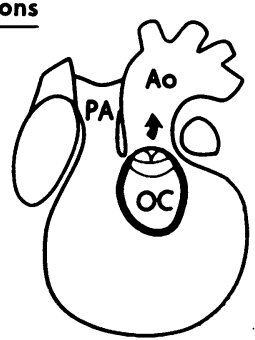

D) L-tronsposition- 2 coses

\section{Transposition}

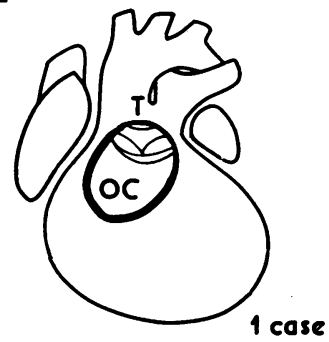

F) Single arterial trunk (persistent truncus arteriosus)

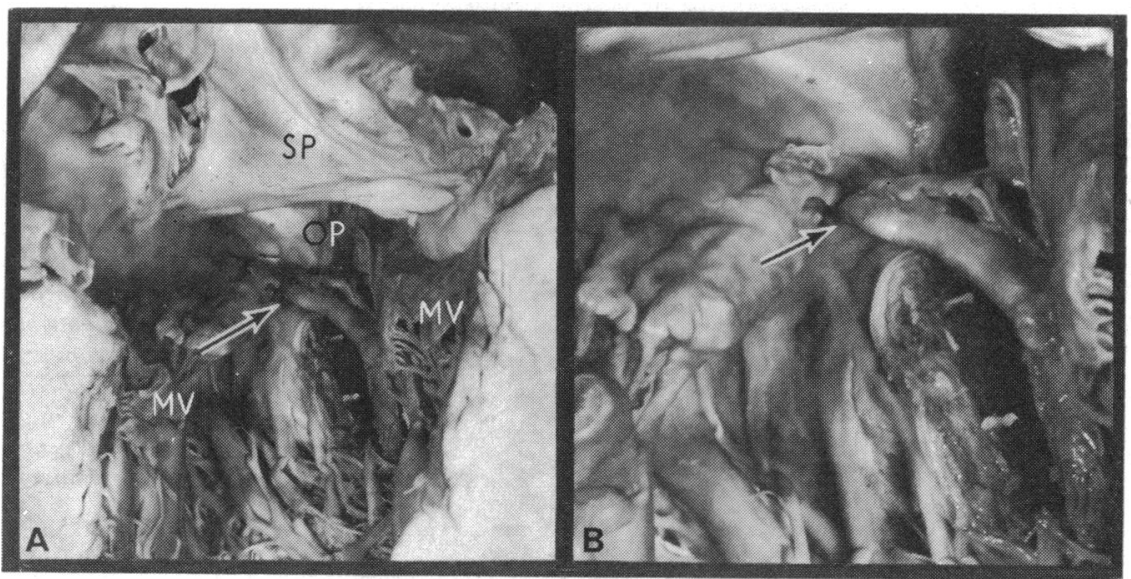

Fig. 5 Photographs of a heart with primitive ventricle and outlet chamber and right atrial orificial atresia, an ostium primum defect, and a cleft mitral valve. (A) View from posterior aspect of main chamber. The free lower edge of the septum primum (SP) is seen, with an ostium primum (OP) defect beneath it. The mitral valve (MV) has a cleft (arrowed) in its anterior leaflet, and the valve orifice extends into the right atrium. The cut seen is through the right lateral wall of the heart. (B) Magnified view of cleft in anterior mitral leaflet. 
feature of right atrial anatomy in approximately a third of the hearts studied was persistence of portions of the embryonic venous valves. In 2 instances the valves were almost complete and partitioned the auricular part of the chamber from the sinus venarum (Gerlis and Anderson, 1976). In one heart, Fontan repair had been attempted, and the Eustachian valve formed a veil across the prosthetic inferior vena caval valve which had been inserted, separating it from the atrial insertion of the conduit. Discrete 'dimples' in the floor of the right atrium were observed in 36 of the hearts studied. The left atrium in all hearts received the pulmonary venous return and, via the interatrial communication, the systemic venous return.

\section{B. VENTRICULAR MORPHOLOGY}

In 6 hearts formed right and left ventricles were identified (Fig. 1). An imperforate membrane was present in the floor of the right atrium separating it from the formed right ventricle. On its ventricular aspect the membrane was attached to hypoplastic valvar tension apparatus. In 4 of the 6 , the right ventricle was small and hypoplastic and the infundibulum was also blind ending. These hearts were, therefore, examples of pulmonary atresia with intact septum. In one the cavity extended as multiple sinusoids into the septum, which bulged into the aortic outflow tract. In the other 2 hearts, the imperforate membrane between right atrium and right ventricle was displaced distally to the

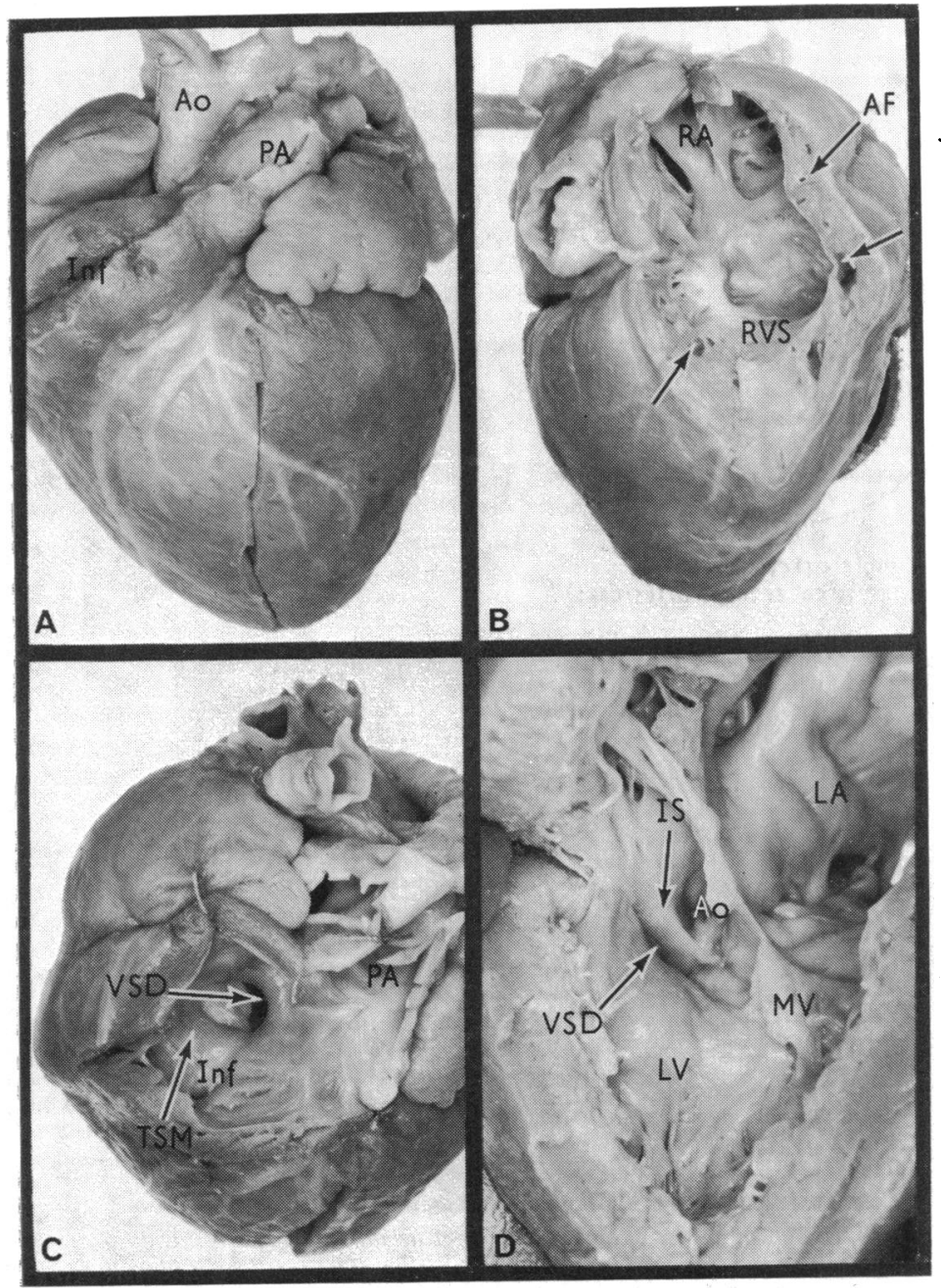

Fig. 6 Photographs of a heart with formed right and left ventricles and an imperforate Ebstein's anomaly. (A) An anterior view of the heart. The arteries (Ao, PA) are normally connected and normally related. $(B)$ The right side of the heart after removal of its right posterolateral wall. The right atrium (RA) leads to the right ventricular sinus (RVS) but egress of blood is blocked by an imperforate tricuspid valve. The ventricular origin of the valve (arrows) is well below the annulus fibrosus ( $A F)$, indicating an Ebstein anomaly. (C) The opened infundibulum (Inf). Blood reaches the pulmonary artery $(P A)$ through a large ventricular septal defect (VSD), and the imperforate tricuspid valve is seen through the defect. Note also the prominent trabecula septomarginalis forming a partial septum between the infundibulum and sinus of the right ventricle. This structure could also be considered a remnant of the bulboventricular septum. (D) The left-sided chamber is a morphological left ventricle (LV). The defect from this chamber to the infundibulum is now bounded by the interventricular septum and the infundibular septum (IS) not by the right bulboventricular ridge as in the hearts with primitive ventricle (vide infra). $L A$, left atrium; $M V$, mitral valve; Ao, aorta. 
junction of ventricular inflow and outflow portions. They were, therefore, examples of imperforate Ebstein's anomaly. One of these has been described elsewhere (Gerlis and Anderson, 1976); the other (Fig. 6) had a large ventricular septal defect between the left ventricle and the right ventricular infundibulum, which supported a good sized pulmonary artery.

In 77 hearts the blind ending right atrium was not in potential communication with an anterior ventricle, but with the same ventricular chamber as received the left atrioventricular valve (Fig. 7 and 8). All these hearts were, therefore, examples of primitive (single or common) ventricle. In one heart (Fig. 7) a fibrous membrane at the site of the dimple formed a discrete aneurysm protruding from the floor of the right atrium into the main chamber. In 36 of the remaining hearts the right atrial 'dimple' overlaid the central fibrous body, and was again the potential communication with the main chamber. In 34 hearts, discrete 'dimples' were not observed, but dissection revealed that the right atrial floor was in potential communication only with the main chamber (Fig. 8). In a further 6 hearts, ostium primum defects existed through which the right atrium was in direct communica-

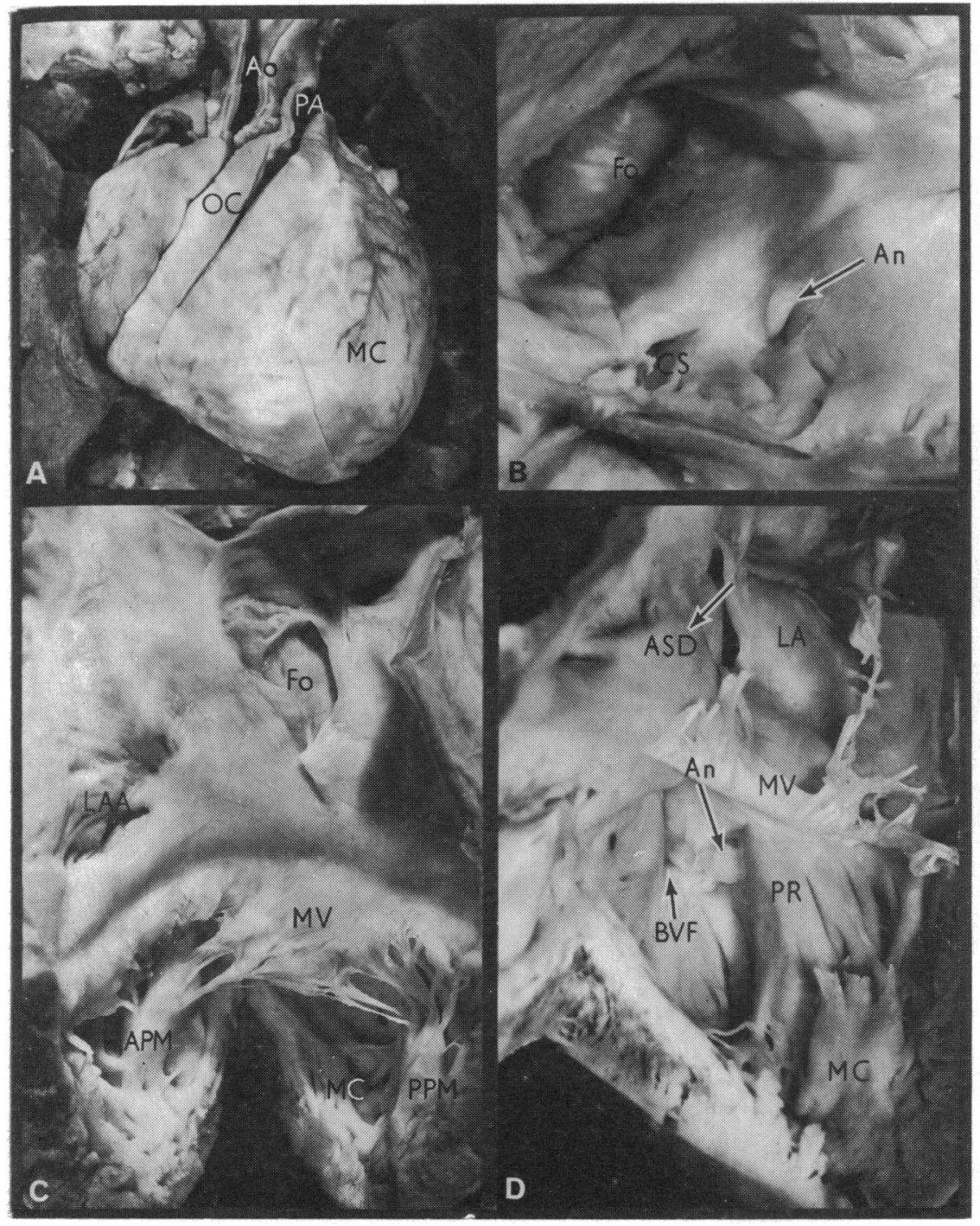

Fig. 7 Photographs of a specimen of primitive ventricle with outlet chamber, right atrial orificial atresia, and with an aneurysmal 'dimple'. (A) Anterior view of the heart (OC, outlet chamber; $M C$, main chamber; Ao, aorta; $P A$, pulmonary artery). (B) Right atrial anatomy. The dimple is large and aneurysmal (An) (FO, foramen ovale; CS, coronary sinus). (C) Left atrium communicating with main chamber through a normal mitral valve (MV) ( $L A A$, left auricular appendage; APM, PPM, anterior and posterior papillary muscles). (D) After retraction of the mitral valve, the aneurysm is seen pointing into the large cleft between the well formed posterior ridge $(P R)$ and the bulboventricular septum. We believe this cleft to represent the unexpanded right ventricular inflow tract (BVF, bulvoventricular foramen). 
tion with the main chamber (Fig. 5). The histological studies in 12 hearts confirmed these atrioventricular relations, and showed that the atrioventricular incisura always interposed between the right atrial floor and the outlet chamber.

In 74 of the 77 hearts the ventricular morphology was that of primitive ventricle with outlet chamber. In the remaining 3 hearts there was only one ventricular chamber, which received the left atrioventricular valve and gave rise to both great arteries (Fig. 9). In primitive ventricle without outlet chamber the ventriculoarterial connection must by definition be one of double outlet (Shinebourne et al., 1976). There was d-malposition in two of these hearts and 1-malposition in the third. When an outlet chamber was present, it was anterior and to the right in 71 specimens and to the left in 3. The outlet chamber morphology varied according to the ventriculoarterial connection. With normal ventriculoarterial connection, the outlet chambers had long infundibular segments and smaller apically trabeculated portions (Fig. 2, 10).'In contrast, when

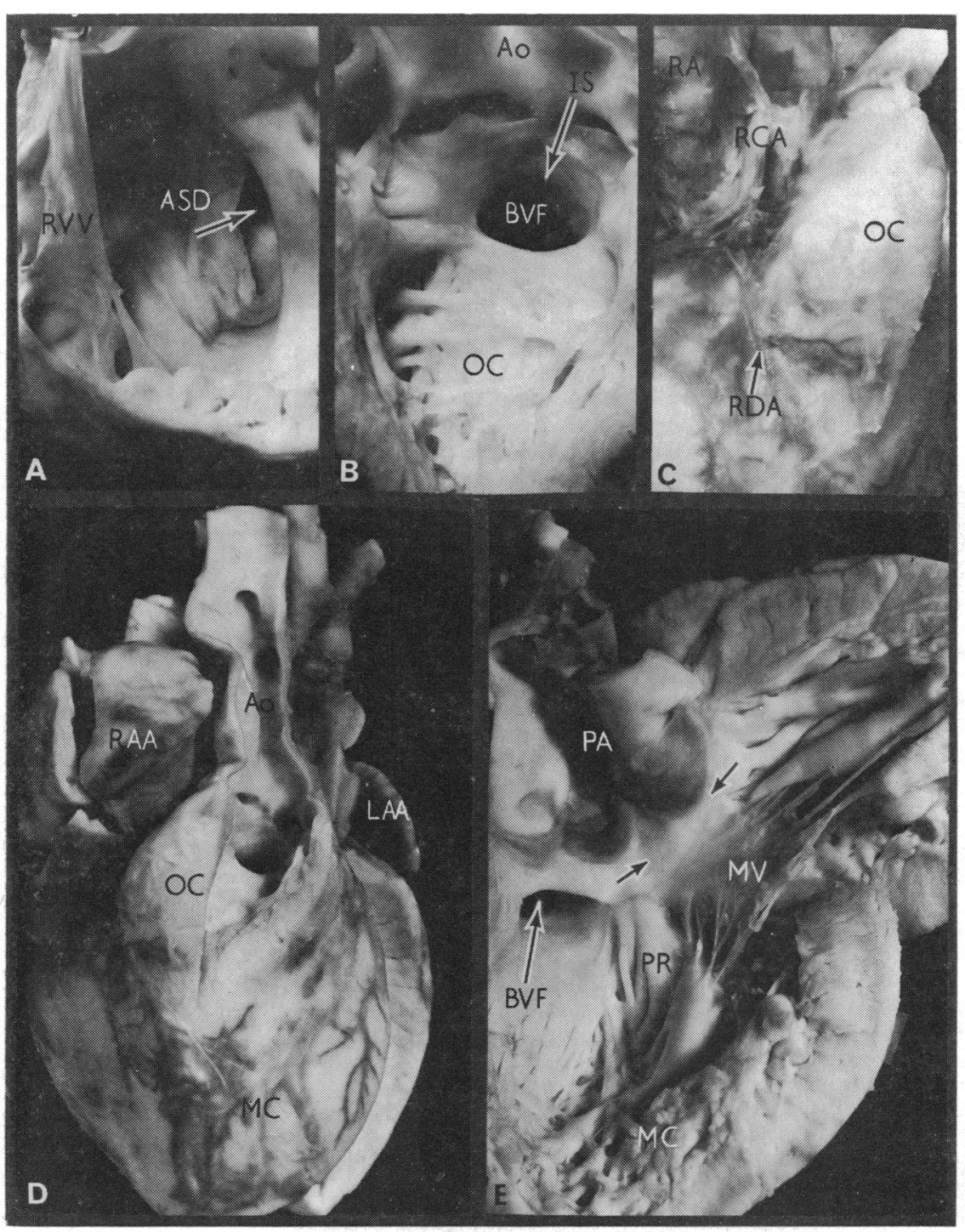

Fig. 8 Photographs of a specimen of primitive ventricle with outlet chamber, right atrial orificial atresia, and transposed great arteries. The general view of the heart is seen in (D) (RAAright auricular appendage). ( $A$ ) Detail of the blindending right atrium. Note the prominent right venous valve $(R V V)$. (B) Detail of the anterior aspect of the opened outlet chamber. Note that the infundibular septum is short so that the bulboventricular foramen opens directly beneath the aortic valve (compare Fig. 8B, 10B). (C) Detail of a right oblique view of the heart. The right coronary artery (RCA) runs between the right atrium and the outlet chamber, and its descending branch (RDA) delimits the outlet chamber. The chamber is not in contact with the right atrium. (E) Main chamber giving rise to the pulmonary artery. Note the prominent posterior ridge and mitral-pulmonary valvar continuity (between arrows). Other abbreviations as before. 
transposition was present the infundibular segment was much shorter and the trabeculated zone more prominent (Fig. 8).

The trabeculations of the main chamber resembled those of the normal left ventricle in all cases, but were frequently much coarser than normal (Fig. 10). There were several other differences between the main chamber and a normal left ventricle. The septal surface was much smaller, was orientated in the frontal plane, and was frequently trabeculated. The bulboventricular defect was separated from the area of the central fibrous body by direct fusion of the infundibular septum with the bulboventricular septum. The aortic valve in hearts with normally connected arteries was, therefore, separated from the defect by a muscular bar, unlike the situation seen in isolated ventricular septal defect with normally connected arteries (compare Fig. 11A and B). Another unusual feature of the main chamber was the presence of a prominent posterior trabeculation. In some hearts this ridge was sufficiently prominent to divide the chamber into large left and smaller right-sided portions (Fig. 10). In all but two hearts the valve entering the main chamber had the morphological characteristics of a mitral valve (Fig. 7, 8). In these two hearts, both with left-sided outlet chambers, there were morphologically tricuspid valves between the left atrium and the main chamber; in both hearts the outlet chamber was larger with a prominent trabeculated pouch and the bulboventricular septum was straddled by the left atrioventricular valve (see Fig. 13). In the other

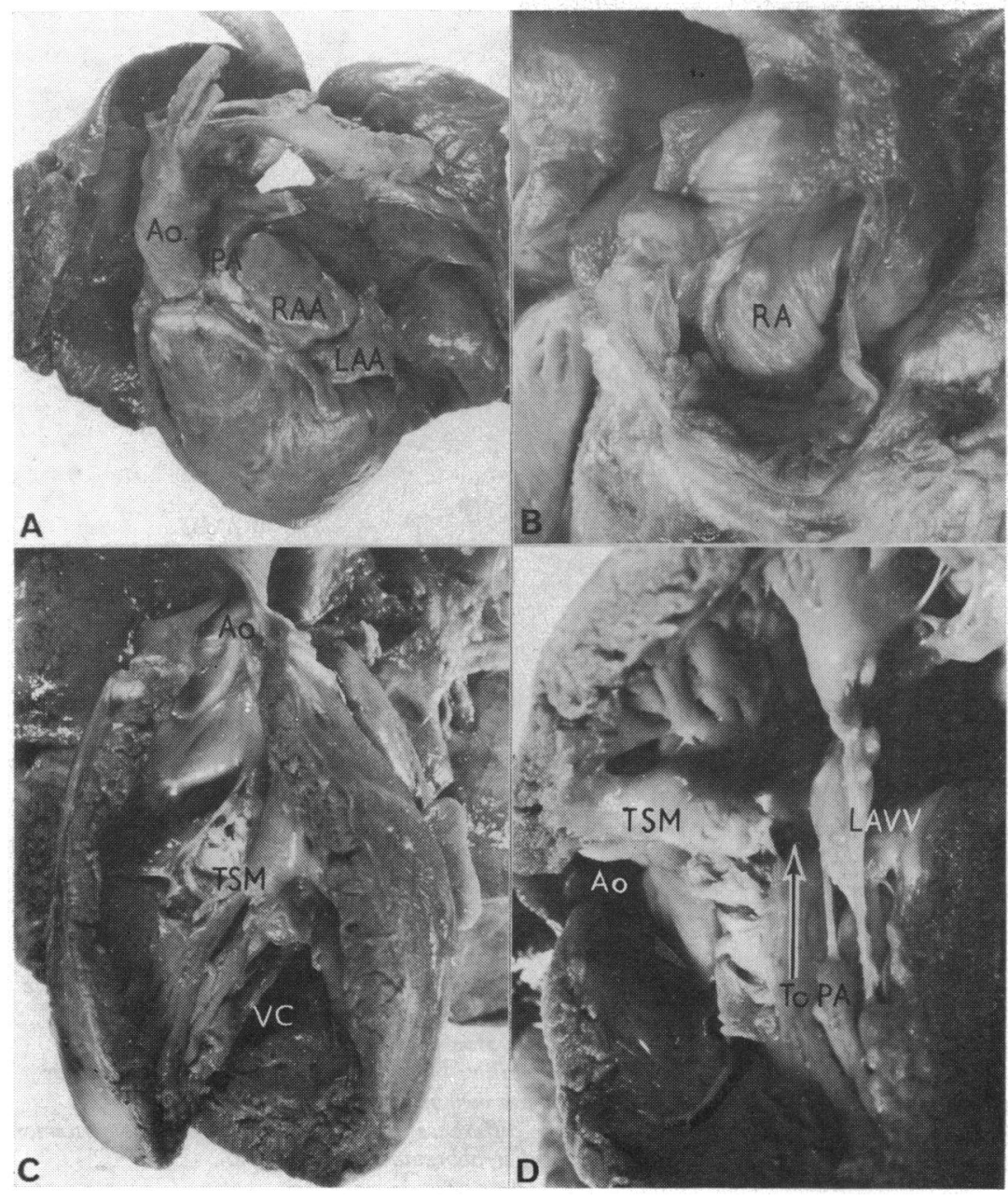

Fig. 9 Photographs of a specimen of primitive ventricle, without outlet chamber, and right atrial orificial atresia. ( $A$ ) The general view of the heart. The auricles ( $R A A, L A A$ ) are juxtaposed to the left of the great arteries, the aorta (Ao) being anterior and to the right of the pulmonary artery (PA). (B) The blind-ending right atrium $(R A)$. (C) The anterior aorta (Ao) arises from the sole ventricular chamber (VC). The cavity of the ventricle is spanned by a free running strand which represents the trabecula septomarginalis (TSM). These relations are better illustrated in (D), taken from the apex of the ventricle. The single chamber receives the left atrioventricular valve ( $L A V V)$ and gives rise to both great arteries $(A o, P A)$, which are separated by the infundibular septum. The ventriculoarterial connection is one of double outlet ventricle. 


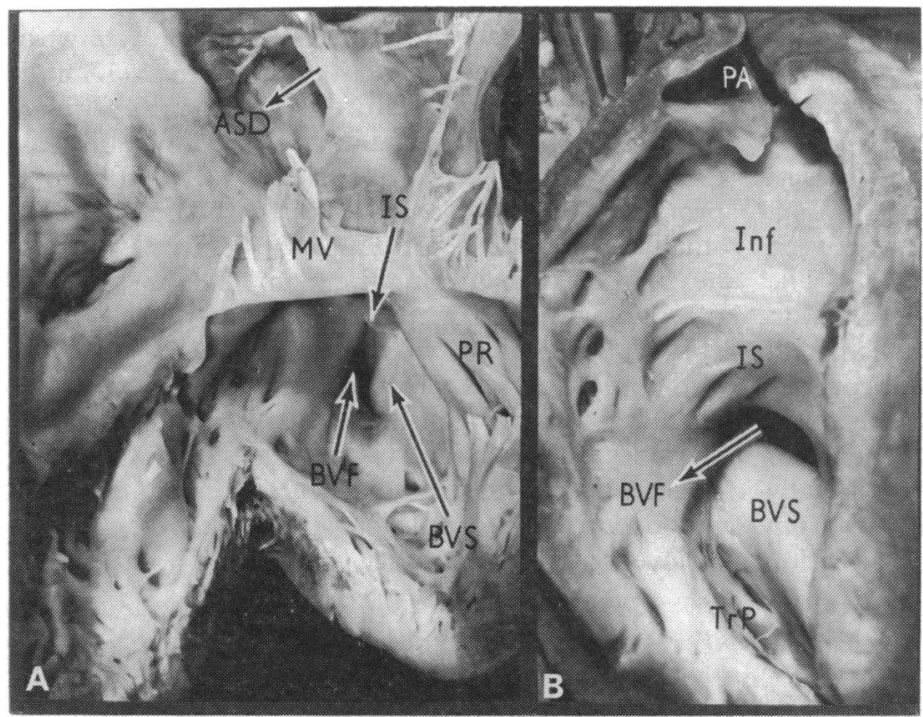

Fig. 10 Further views of the case of primitive ventricle with outlet chamber, right atrial orificial atresia, and aneurysmal 'dimple' illustrated in Fig. 7. (A) The relation of the bulboventricular foramen to the posterior ridge. The inferior edge of the infundibular septum (IS) and the bulboventricular septum (BVS) separate the dimple from the outlet chamber. (B) The anterior aspect of the outlet chamber. It differs in morphology from that seen in Fig. 8, by virtue of the deep infundibulum (Inf) beneath the pulmonary valve. It possessed an extensive trabeculated apical pouch ( $\operatorname{Tr} P)$. However, it does not contain tension apparatus and does not receive the aneurysmal dimple (see Fig. 7).

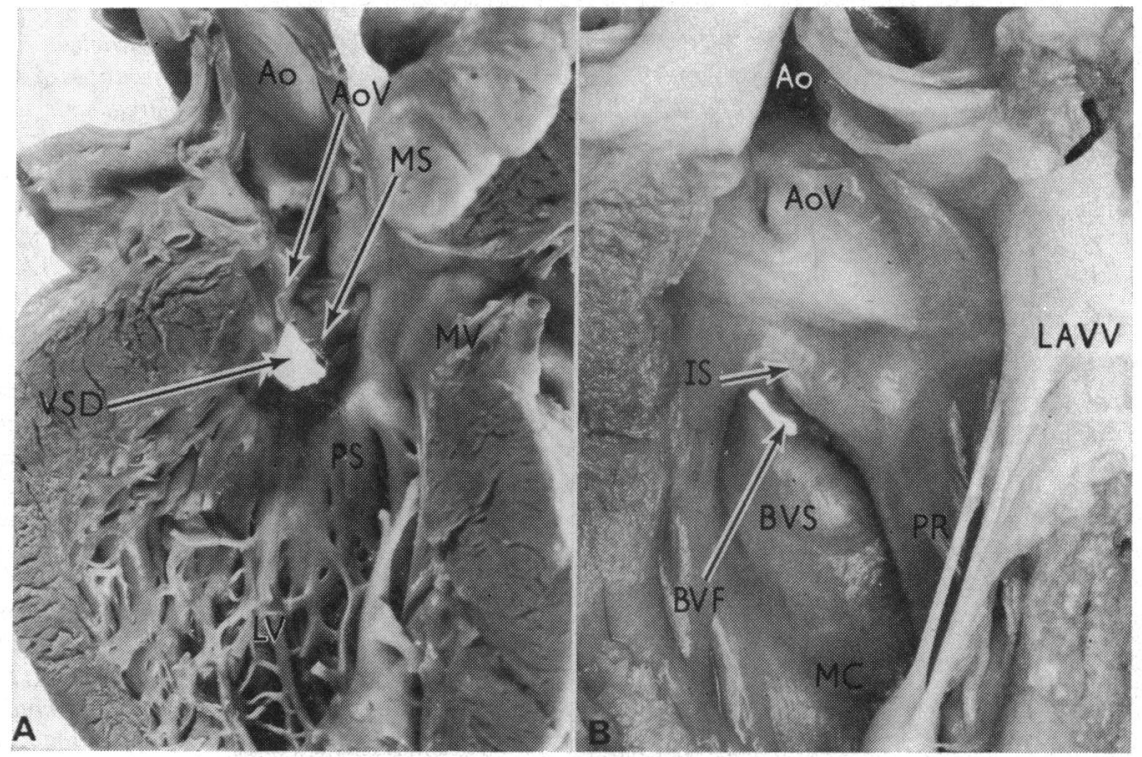

Fig. 11 Photographs illustrating the differences between an isolated ventricular septal defect (VSD) in a heart with atrioventricular concordance $(A)$, and a secondary bulboventricular foramen (BVF) in a heart with primitive ventricle with outlet chamber and right atrial orificial atresia $(B)$. (A) Vieved from the left ventricle $(L V) ;(B)$ from the main chamber (MC). Note that in the isolated defect, the roof is the aortic valve (AoV) and the partially formed interventricular segment of the membranous septum (MS). Because of the failure of formation of the right ventricular inflow tract in the specimen shown in (B), the interventricular segment of the membranous septum is lacking. The foramen is bounded instead by the infundibular septum (IS). Note also the difference in orientation between the posterior interventricular septum (PS) and the bulboventricular septum (BVS). Other abbreviations as above. 
specimen with right atrial orificial atresia and leftsided outlet chamber the left atrioventricular valve was morphologically a mitral valve (Fig. 12).

\section{VENTRICULOARTERIAL CONNECTIONS}

All the 6 hearts with atrioventricular concordance (right atrium separated from right ventricle by imperforate membrane) had normal ventriculoarterial connections, albeit with pulmonary atresia in 4 cases. Connections were very variable when the ventricular morphology was that of primitive ventricle (Fig. 4). Normal connections (60 of 77 hearts) were most frequently encountered, usually with normal relations $(58$ of 60 ). Four of these hearts had pulmonary atresia. Two of the hearts with normal connections had 1-malpositioned aortae (anatomically corrected malposition). Twelve hearts had transposition, 10 with d-transposed aortae. It was noteworthy that 1 of 2 cases with 1-transposition had a left-sided mitral valve. The 3 hearts without outlet chambers had double outlet chambers by definition, 2 with d- and 1 with 1-malposition. One additional heart had a double-outlet connection, from the outlet chamber. One specimen had a persistent truncus arteriosus.

\section{PULMONARY AND AORTIC STENOSIS}

The most frequent source of stenosis was a constrictive bulboventricular foramen in hearts with primitive ventricle. Such a constriction produced

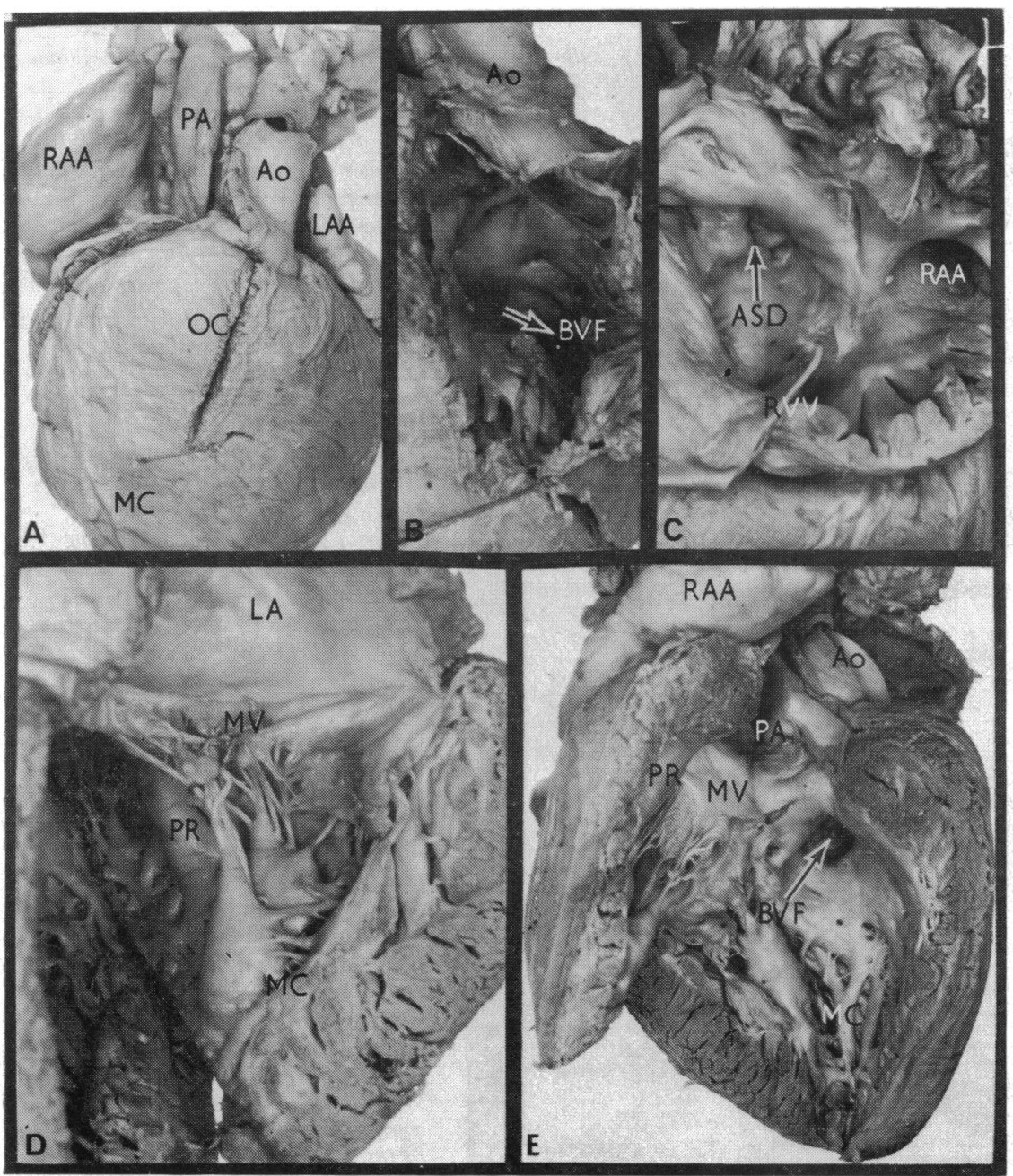

Fig. 12 Photographs of a heart with primitive ventricle outlet chamber, right atrial orificial atresia, and l-transposition. ( $A$ ) Anterior view of the heart. The outlet chamber is anterior to the main chamber and the aorta is left sided. The opened outlet chamber is seen in (B). It is small and the bulboventricular foramen opens directly beneath the aortic valve. (C) The blindending right atrium. Note the prominent venous valve ( $R V V)$. (D) Main chamber opened from behind and from the left. Note the typical mitral valve and the prominent posterior ridge ( $P R$ ).

(E) Vieved from the right through the cut visible in (D). The front of the mitral valve is seen with pulmonary-mitral valvar continuity. Despite the presence of right atrial orificial atresia and a left-sided mitral valve the aorta and bulboventricular foramen (BVF) are both left sided. Other abbreviations as above. 
pulmonary stenosis in 30 hearts with normally connected arteries, and aortic stenosis with associated isthmal hypoplasia in 5 hearts with transposition (Fig. 14). Another source of pulmonary stenosis in the presence of normal connections was a constriction between the trabeculated and infundibular segments of the outlet chamber; this was seen in 4 hearts in addition to stenosis at the bulboventricular foramen. Valvar stenosis also frequently accompanied bulboventricular stenosis but in 3 cases was the sole cause. In one further case, fibrous tissue from the underside of the infundibular septum obstructed the bulboventricular foramen. Pulmonary stenosis was not seen in association with transposition.

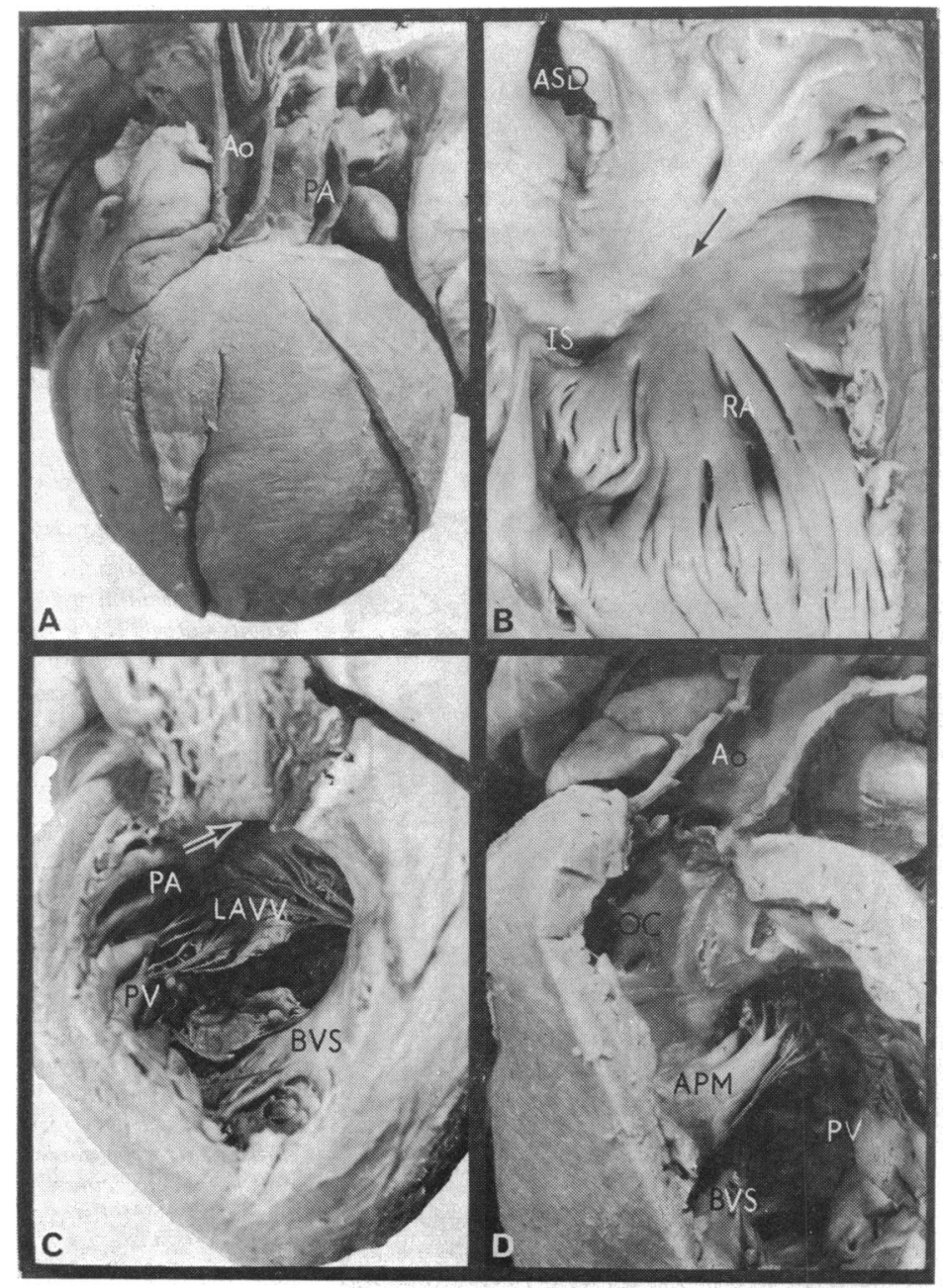

\section{E. ADDITIONAL ANOMALIES}

Juxtaposition of the auricles was encountered in 4 hearts. Three had 1-malpositioned aortae, 2 of these with normal ventriculoarterial connections (anatomically corrected malposition).

\section{Discussion}

Our investigation has shown, as others have found before (Okin et al., 1969; Van Praagh et al., 1971;

Fig. 13 Photographs of a heart with primitive ventricle, outlet chamber, right atrial orificial atresia, straddling left atrioventricular valve, and d-transposition. (A) Anterior view of the heart. Note the rightsided aorta and the position of the two incisions into the ventricular mass. (B) The interior of the right atrium. It is blind ending with a small dimple (arrowed). The only route for systemic venous blood is through the atrial septal defect. (C) Ventricular morphology viewed through the right-sided incision. The cavity is divided into a large right-sided posterior chamber (PV) and a smaller left-sided chamber by an oblique septum. We believe this septum to be the bulboventricular septum ( $B V S$ ). The valve taking blood from the left atrium straddles this septum and has the appearance of a morphological tricuspid valve (LAVV). Note the multiple posterior papillary muscles arising from the primitive ventricle, and the single anterior muscle from the outlet chamber tethering the anterior cusp (see D). The pulmonary artery arises from the primitive ventricle and there is pulmonary-tricuspid valvar fibrous continuity. (D) Ventricular morphology as seen through the left-hand incision. The small anterior outlet chamber is left sided but its outlet portion sweeps to the right to give rise to the rightsided aorta. Note the prominent anterior papillary muscle (APM) straddling the bulboventricular septum. Despite the fact that the left-sided valve present has the appearance of a tricuspid valve, in functional terms this heart has right atrial orificial atresia and is comparable to the hearts illustrated in the previous figures. 


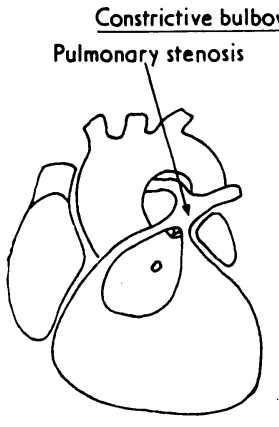

a) Normal connections

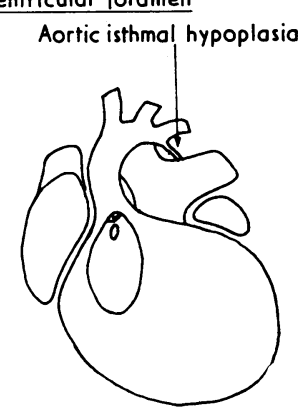

b) Transposition
Fig. 14 Diagram showing that the physiological consequences of bulboventricular construction depend upon ventriculoarterial connections. When the arteries are normally connected, pulmonary stenosis will be produced. In the presence of transposition, aortic stenosis will ensue with the likely sequel of aortic isthmal hypoplasia.

Rao et al., 1973) that there is considerable variation in ventricular morphology in hearts with atresia of the right atrioventricular orifice. Furthermore, as shown by both Henry and Danielson (1974) and Quero-Jimenez et al. (1975) there are further variations in ventriculoarterial connections than merely 'normal relations' or 'transposition'. The question is then posed as to how all these variations can best be described. We believe that adequate description and classification can only be produced by use of the segmental approach (Van Praagh, 1972; Shinebourne et al., 1976). However, it became evident that application of such a segmental approach gave rise to many potential controversies.

\section{A. WHY RIGHT ATRIOVENTRICULAR ORIFICIAL ATRESIA RATHER THAN TRICUSPID ATRESIA?}

In this investigation we have described hearts in which the right atrial chamber was blind ending. In all but 2 of these hearts the valve present between the left atrium and the ventricular chamber was a morphologically mitral valve. However, in the 2 remaining hearts the left-sided valve bore more resemblance to a morphologically tricuspid valve. The morphological inference to be drawn from this information is that d-bulboventricular looping occurred in all but the 2 hearts with left-sided tricuspid valves, in which 1-looping is presumed to have occurred. Would it not therefore be more accurate to separate these 2 hearts as mitral atresia? Morphologically this would be completely acceptable. However, we submit that in clinical terms the important feature is that the right atrium is blind ending, irrespective of whether the atretic valve is morphologically mitral or tricuspid. Furthermore, we believe that it would not be possible angiographically to distinguish a mitral valve from a tricuspid valve. The clinical evidence for $1-$ looping would be inferential, being deduced from presence of a left-sided outlet chamber. Yet one of the hearts presently studied (Fig. 12) possessed a left-sided outlet chamber supporting an 1-transposed aorta; these observations suggest 1-looping but the left atrioventricular valve was morphologically a mitral valve. We, therefore, consider it more accurate and less confusing to refer to 'right atrioventricular orificial atresia' (or 'right atrial orificial atresia'). We have thus excluded from this series hearts with evidence of 1-bulboventricular looping and left atrial orificial atresia. In morphological terms this condition represents 'tricuspid atresia' (Harris and Farber, 1939; Keith et al., 1958), but we prefer to consider it as left atrioventricular orificial atresia, and we would group it together with other forms of primitive ventricle which exhibit blind-ending left atria (Quero, 1970; Macartney et al., 1976).

\section{B. CAN RIGHT ATRIOVENTRICULAR ATRESIA COEXIST WITH PRIMITIVE VENTRICLE?}

As Macartney and his colleagues (1976) have recently indicated, it has become customary to exclude by definition from the category of primitive (single or common) ventricle, cases of atrioventricular valve atresia. They concluded that in terms of angiography this exclusion was unjustified, a view previously put forward by Quero (1970). Our investigation fully endorses their opinions, and shows that the majority but not all of our examples of right atrioventricular valve atresia are more akin to primitive ventricle than to hearts with normal right and left ventricles. Van Praagh et al. (1964) did not expand on their reasons for excluding cases with atrioventricular valve atresia from single ventricle. Lev and his colleagues (1969) believed that the differentiation depended on whether the main chamber contained the undeveloped right ventricular inflow portion in a position in which it was related to the atretic orifice. They conceded the possibility that this might indeed be the case in hearts with transposition, as previously suggested by Edwards et al. (1965). However, they stated that this was not the case with normally connected arteries, citing as evidence the fact that conducting tissue studies had demonstrated a right bundlebranch entering the outlet chamber. Our own histological observations are in agreement with theirs, but our interpretation differs. We have observed a 
similar distribution of conducting tissues in the outlet chamber in primitive (single) ventricle (Anderson et al., 1974a). Furthermore, our histological studies in right atrioventricular orificial atresia have shown that the atretic orifice does indeed 'point' to the main chamber. This fact indicates to us that the hearts thus fulfil the criterion demanded by Lev $e t$ al. for single ventricle, since we believe that the right ventricular inflow portion is indeed contained within the main chamber, which therefore constitutes a primitive ventricle. As in 'single' or 'common' ventricle with outlet chamber, the outlet chamber represents the embryonic bulbus (Keith, 1906). We suggest that in primitive ventricle with two atrioventricular valves, the right inflow portion has developed with persistence of the bulboventricular septum in its initial anterior position, whereas in right atrioventricular orificial atresia there has been lack of development of the inflow portion but persistence of the anteriorly situated bulboventricular septum (Fig. 15). This concept is supported by the previous study of Rosenquist

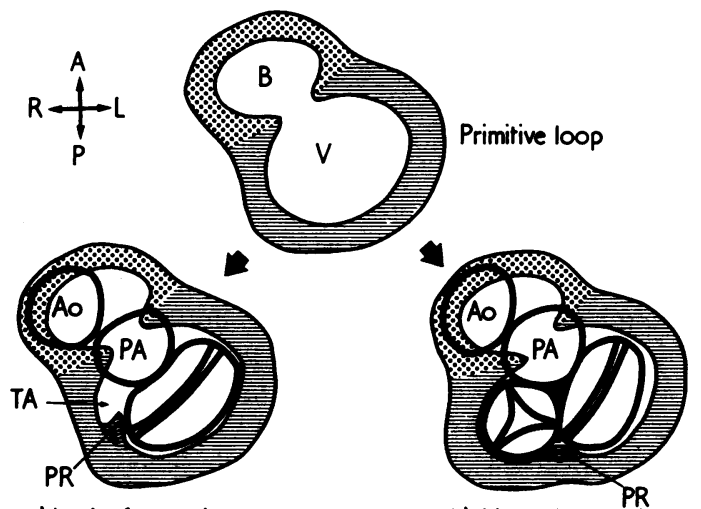

a) Lack of expansion

b) Normal expansion

Fig. 15 Diagrams illustrating the morphogenetic link between primitive ventricle with outlet chamber and two atrioventricular valves (lower right hand diagram) and primitive ventricle with outlet chamber and right atrial orificial atresia (lower left hand diagram). Both represent persistence of that stage of development where the bulbus (outlet chamber:B) is separated from the primitive ventricle (main chamber: $V$ ) by the bulvoventricular septum. In primitive ventricle with right atrial orificial atresia, it can be hypothesised that there has been failure of development of the inflow tract of the right ventricle, derived from the primitive ventricle. In primitive ventricle with two atrioventricular valves, the right ventricular inflow tract is developed, but is separated from the outlet chamber (bulbus) by the persistent bulboventricular septum. (Reproduced from Anderson et al., British Heart Journal, 38, 558, 1976.) et al. (1970), who showed most elegantly that the atretic right atrioventricular orifice was potentially in communication with the 'left' ventricle rather than the 'right'. In view of this evidence, it seems to us proper that the definition of primitive (single or common) ventricle should be modified as suggested by Macartney et al. (1976). Thus, if primitive ventricle exists when both atria are either actually or potentially in communication with the same ventricular chamber, then the majority of specimens of right atrioventricular valve atresia can properly be classified as primitive ventricle (Anderson et al., 1976).

It must be emphasised once more that not all cases of right atrioventricular orificial atresia are cases of primitive ventricle. Six of our cases had true right ventricles. Four of these had right ventricular hypoplasia, comparable with the cases reported by Okin et al. (1969). The remaining cases had imperforate Ebstein's anomaly of the right atrioventricular valve. This rare condition was well documented by Rao et al. (1973) who reviewed previous cases and emphasised the clinical importance of its recognition.

\section{ASSOCIATED ANOMALIES}

The clinical importance of the classification of Edwards and Burchell (1949) was that it described the state of pulmonary blood flow. In order to convey this important information, Henry and Danielson (1974) tabulated their extensive findings, using a modification of this approach. However, the segmental approach does not preclude the provision of this information if it is appreciated that pulmonary stenosis is an associated anomaly. An important and vital part of segmental nomenclature is the tabulation of additional anomalies. In this way other information will also be transmitted and attention focused on the genesis of these associated anomalies. Thus pulmonary stenosis with right atrioventricular orificial atresia is most frequently the result of a constrictive bulboventricular foramen. If one thinks segmentally it is readily apparent that a similar constriction in the presence of transposition will result in aortic stenosis and associated isthmal hypoplasia. When pulmonary stenosis occurs with transposition, it must have a different cause, usually posterior deviation of the infundibular septum.

\section{SURGICAL SIGNIFICANCE}

With the demonstration by Fontan and Baudet (1971) that radical palliative surgery is possible in the presence of right atrial orificial atresia, knowledge of all aspects of anatomy is vital. It will immediately be evident that hearts with formed right ventricles do not require a Fontan-type procedure. In one of the 
hearts we have described, excision of an imperforate Ebstein anomaly would have restored the normal circulatory pattern (Fig. 6). Rao et al. (1973) have previously commented on the surgical importance of recognising this variety of right atrial orificial atresia. It is because of the surgical implications that we have excluded from this series hearts with left atrial orificial atresia even when the atretic valve was morphologically tricuspid. Since the Fontan operation can be employed only when the right atrium is blind ending, we prefer to distinguish between right and left atrial orificial atresia, rather than between tricuspid and mitral atresia.

The fact that a small number of the hearts were examples of primitive ventricle without outlet chamber may also be significant. It is becoming customary now to insert the distal end of the right atrial conduit to the outlet chamber. Clearly this would be impossible when an outlet chamber is not present. In the hearts we studied an outlet chamber was also effectively lacking when there was pulmonary atresia with normal ventriculoarterial connections. However, in all other hearts a good size outlet chamber was present even when secondary constriction of the bulboventricular foramen had occurred. In 4 hearts a second constriction was present distally within the outlet chamber which may have detracted from its functional valus as a potential pumping chamber if the distal end of the conduit had been inserted to that chamber.

The type of ventriculoarterial connection present also influences the site of insertion of the distal end of the conduit. The outlet chamber can only be employed as part of the pulmonary circuit in the presence of normally connected arteries. It is important to realise, therefore, that normal ventriculoarterial connections can exist with an anterior leftsided aorta. This relation is usually termed anatomically corrected malposition, and its association with right atrial orificial atresia has previously been stressed by Melhuish and Van Praagh (1968) and by Freedom and Harrington (1974). It must also be remembered that any possible ventriculoarterial connection can exist with right atrial orificial atresia.

\section{Conclusions}

In summary, therefore, we believe that our study has shown a basic subdivision in terms of ventricular morphology in hearts with atresia of the right atrioventricular orifice, the majority being examples of primitive ventricle with outlet chamber. We believe that understanding of the condition is enhanced if the anomaly is described as right atrial orificial atresia rather than 'tricuspid atresia' since in some hearts the atretic orifice may be a mitral orifice, but nevertheless its effect is to shunt systemic venous return to the left atrium. Finally, we believe that our investigation endorses once more the value of a segmental approach to diagnosis (Van Praagh, 1972; Shinebourne et al., 1976), since many variants of right atrial orificial atresia are described, while others probably exist which have yet to be described.

We are indebted to all our clinical colleagues for permission to study hearts from patients previously in their care. We are also indebted to colleagues who placed their specimens at our disposal, in particular Drs. J. Van Gorp and Sj. Sc. Wagenaar of Utrecht and Dr. Oppenheimer-Decker of Leiden. We were greatly assisted in the final preparation of the manuscript and illustrations by Miss N. de Freitas and Mrs. S. Y. Ho.

\section{References}

Anderson, R. H., Arnold, R., Thapar, M. K., Jones, R. S., and Hamilton, D. I. (1974a). Cardiac specialized tissue in hearts with an apparently single ventricular chamber (double inlet left ventricle). American fournal of Cardiology, 33, 95-106.

Anderson, R. H., Wilkinson, J. L., Arnold, R., Becker, A. E., and Lubkiewicz, K. (1974b). Morphogenesis of bulboventricular malformations: II Observations on malformed hearts. British Heart fournal, 36, 948-970.

Anderson, R. H., Becker, A. E., Wilkinson, J. L., and Gerlis, L. M. (1976). Morphogenesis of univentricular hearts. British Heart fournal, 38, 558-572.

Edwards, J. E., and Burchell, H. B. (1949). Congenital tricuspid atresia: a classification. Medical Clinics of North America, 33, 1177-1196.

Edwards, J. E., Carey, L. S., Neufeld, H. N., and Lester, R. G. (1965). Congenital Heart Disease, p. 358. W. B. Saunders, Philadelphia.

Fontan, F., and Baudet, E. (1971). Surgical repair of tricuspid atresia. Thorax, 26, 240-248.

Freedom, R. M., and Harrington, D. P. (1974). Anatomically corrected malposition of the great arteries. Report of 2 cases, one with congenital asplenia; frequent association with juxtaposition of atrial appendages. British Heart fournal, 36, 207-215.

Gerlis, L. M., and Anderson, R. H. (1976). Cor Triatriatum dexter with imperforate Ebstein's anomaly. British Heart fournal, 38, 108-111.

Harris, J. S., and Farber, S. (1939). Transposition of the great cardiac vessels. Archives of Pathology, 28, 427-502.

Henry J. N., and Danielson, G. K. (1974). Successful 'correction' of tricuspid atresia: results of a detailed anatomical study. Surgical Forum, 25, 163-165.

Keith, A. (1906). Malformations of the bulbus cordis. An unrecognized division of the human heart, p. 55. Quarcentenary Studies in Pathology, Edinburgh.

Keith, J. D., Rowe, R. D., and Vlad, P. (1958). Heart Disease in Infancy and Childhood, p. 437. Macmillan, New York.

Lev, M., Liberthson, R. R., Kirkpatrick, J. R., Eckner, F. A. O., and Arcilla, R. A. (1969). Single (primitive) ventricle. Circulation, 39, 577-591.

Macartney, F. J., Partridge, J. B., Scott, O., and Deverall, P. B. (1976). Common or single ventricle: an angiocardiographic and hemodynamic study of 42 patients. Circulation, 53, 543-554. 
Melhuish, B. P., and Van Praagh, R. (1968). Juxtaposition of the atrial appendages; a sign of severe cyanotic congenital heart disease. British Heart fournal, 30, 269-284.

Okin, J. T., Vogel, J. H. K., Pryor, R., and Blount, S. G. (1969). Isolated right ventricular hypoplasia. American fournal of Cardiology, 24, 135-140.

Quero, M. (1970). Atresia of the left atrioventricular orifice associated with a Holmes heart. Circulation, 42, 739-744.

Quero-Jimenez, M., Maître Azcárate, M. J., Alvarez Bejarano, H., and Vazquez Martul, E. (1975). Tricuspid atresia, an anatomical study of seventeen cases. European fournal of Cardiology, 3, 337-348.

Rao, P. S., Jue, K. L., Isabel-Jones, J., and Ruttenberg, H. D. (1973). Ebstein's malformation of the tricuspid valve with atresia. American fournal of Cardiology, 32, 1004-1009.

Rosenquist, G. C., Levy, R. J., and Rowe, R. D. (1970). Right atrial-left ventricular relationships in tricuspid atresia: position of the presumed site of the atretic valve as determined by transillumination. American Heart fournal, 80, 493-497.

Shinebourne, E. A., Macartney, F. J., and Anderson, R. H. (1976). Sequential chamber localization: logical approach to diagnosis in congenital heart disease. British Heart Fournal, 38, 327-340.
Tandon, R., and Edwards, J. E. (1974). Tricuspid atresia. A re-evaluation and classification. Fournal of Thoracic and Cardiovascular Surgery, 67, 530-542.

Van Mierop, L. H. S., Alley, R. D., Kausel, H. W., and Stranahan, A. (1963). Pathogenesis of transposition complexes: I Embryology of the ventricles and great arteries. American fournal of Cardiology, 12, 216-225.

Van Praagh, R. (1972). The segmental approach to diagnosis in congenital heart disease. Birth Defects: Original Article Series, 8, 4 .

Van Praagh, R., Ando, M., and Dungan, W. T. (1971). Anatomic types of tricuspid atresia: clinical and developmental implications (abstract). Circulation, 43-44, Suppl. 2, 115.

Van Praagh, R., Ongley, P. A., and Swan, H. J. C. (1964). Anatomic types of single or common ventricle in man. American fournal of Cardiology, 13, 367-386.

Requests for reprints to Dr. R. H. Anderson, Department of Paediatrics, Cardiothoracic Institute, Brompton Hospital, Fulham Road, London SW3 $6 \mathrm{HP}$. 